\title{
The Benefits of a Life-first employment program for Indigenous Australian families: Implications for 'Closing the Gap'
}

\section{Lynsey Brown}

Southgate Institute for Health, Society and Equity

Flinders University

\section{Katy Osborne}

Southgate Institute for Health, Society and Equity Flinders University

\section{Ruth Walker}

Southgate Institute for Health, Society and Equity Flinders University

\section{Megan Moskos}

National Institute of Labour Studies

Flinders University

Linda Isherwood

National Institute of Labour Studies

Flinders University

\section{Katherine Patel}

Southgate Institute for Health, Society and Equity Flinders University

\section{Fran Baum}

Southgate Institute for Health, Society and Equity

Flinders University

\section{Debra King}

School of Social and Policy Studies

Flinders University 
There are significant and enduring inequities in education and employment outcomes between Indigenous and non-Indigenous Australians. In taking a 'life-first' approach to service provision the Building Family Opportunities Program (BFO) was able to successfully increase Indigenous Australians' engagement with education and employment in South Australia. The evaluation of the BFO included quantitative administrative and survey data for 110 Indigenous families collected over a three year period, and qualitative data from interviews with 13 Indigenous jobseekers and focus groups with 24 case managers. Quantitative data revealed that similar proportions of Indigenous and non-Indigenous jobseekers achieved positive education/training and employment outcomes as a result of the program. Qualitative data were able to identify the strengths of this program as perceived by Indigenous families and case managers, including the practical and socioemotional support offered to whole families, using a strengths-based, life-first approach. In the context of broader education and employment disadvantages experienced by Indigenous Australians, these results are significant and illustrate key lessons which can inform future policy and service delivery initiatives aiming to close the gap.

Keywords: Indigenous, case management, disadvantage, employment, education, training

South Australia (SA) has the highest rates of unemployment in Australia; in 2015 the national rate was $5.8 \%$, compared to $7.4 \%$ in SA (Australian Bureau of Statistics [ABS], 2015) and for Indigenous South Australians the rate is as high as 15\% (ABS, 2012). Indigenous South Australians exhibit lower: school attendance, high school retention rates, Vocational Education and Training (VET) completions and participation in higher education, as compared to non-Indigenous South Australians (Hetzel, Page, Glover, \& Tennant, 2004). Low education and unemployment have been linked with economic and social disadvantages including poor income, low quality housing, social exclusion and poor health outcomes (Gray, Hunter, \& Lohoar, 2012). Such challenges have a cumulative effect not only for individuals but across generations. Subsequently, in addressing this problem programs designed to encourage South Australians' engagement with the education and employment sectors have been introduced.

There are inequities between Indigenous and non-Indigenous Australians in a range of domains. Outcomes experienced by Indigenous Australians reflect a complex pattern of disadvantage and historical dispossession. Indigenous Australians often experience a high level of discrimination and racism (Paradies \& Cunningham, 2009) which can act as a barrier to education, employment and housing opportunities. As a result, Indigenous Australians have significantly lower income and wealth than non-Indigenous Australians, compounding their disadvantage (Anderson et al., 2007; Carson et al., 2007; Osborne, Baum, \& Brown, 2013). Other factors which have been identified as driving this disadvantage including the overarching impact of colonisation, including the separation of Indigenous Australians from their natural families; the disruption of Indigenous peoples' connections to land, culture and traditions; high rates of incarceration; and society's limited understanding of Indigenous culture (Commission on Social Determinants of Health, 2007; Matthews \& Burton, 2013). Addressing social and economic determinants of health and wellbeing in order to 'Close the Gap' between Indigenous and non-Indigenous Australians has been a priority for State/Territory and Federal Governments, especially in recent years (Council of Australian Governments, n.d.).

Policy initiatives targeting disadvantages experienced by Indigenous Australians have focused on closing the gap in life expectancy; child mortality rates; access to early childhood education; reading, writing and numeracy; Year 12 attainment; and employment outcomes (Australian Government, 2016). One of the Closing the Gap strategy's main aims is to halve the gap in employment outcomes between Indigenous and non-Indigenous Australians by 
2018. A 2016 progress report suggests there is still significant progress to be made; while there has been some positive movement on the educational goals, the employment target is not being met (Australian Government, 2016).

Indigenous Australians experience significant educational and vocational disadvantage. In 2012-13, three times as many Indigenous as non-Indigenous Australians reported educational attainment below Year 10; and only 46\% of Indigenous Australians had completed Year 12 or a Certificate III or above, compared to $73 \%$ of non-Indigenous Australians (ABS, 2014). The 2014-15 National Aboriginal and Torres Strait Islander Social Survey (NATSISS) reinforced this, with $46 \%$ of Indigenous Australians completing Year 12 or a Certificate III and 22\% reporting 'below Year 10' as their highest level of education (ABS, 2016).

The national unemployment rate for Indigenous Australians aged over 15 years is $21 \%$, more than three times the rate for the general population (ABS, 2016). Furthermore, Indigenous workers are more likely to be employed in 'low status' occupations, have more insecure attachments to the labour force, and be exposed to more occupational health risks (Gray et al., 2012). It has also been argued that given a history of discrimination and exploitation in work, and the likelihood that some education/training and employment opportunities will require Indigenous Australians to sacrifice cultural traditions, relocate and separate from their kin networks; many Indigenous people may choose not to participate in the labour market (Dockery \& Milsom, 2007; Kendall, 2001; Lowry \& Moskos, 2007; Penman, 2008). As a result of these trends, Indigenous Australians have fewer financial resources, greater uptake of welfare benefits, and higher levels of financial stress than nonIndigenous Australians (ABS, 2009; Osborne et al., 2013; Walter \& Mooney, 2007).

There is evidence to suggest that supporting Indigenous Australians to undertake education/training and gain employment will have a range of positive consequences. Indigenous Australians with higher educational attainment are likely to experience lower levels of social and economic disadvantage; including higher likelihood of employment and living in a house owned by a householder, and lower likelihood of living in overcrowded housing and involvement with the criminal justice system (ABS, 2011; Kendall, 2001). It has also been suggested that higher educational attainment is positively correlated with better self-rated health and happiness among Indigenous Australians (Biddle \& Cameron, 2012), with similar benefits described for employment (Gray et al., 2014; Hunter \& Gray, 2013).

Despite there being a raft of services and programs aimed at getting jobseekers into work, it can be difficult for unemployed Indigenous Australians to engage in education and training opportunities, or find employment. The NATSISS data reported that $56 \%$ of unemployed Indigenous Australians had spent up to 12 months looking for work before gaining employment, while $25 \%$ had spent more than a year (ABS, 2016). Barriers included transport/distance to employment, limited jobs in the geographical area and industry of choice, childcare availability, long-term health conditions or disability, and insufficient skills. Of the NATSISS participants, $30 \%$ described the latter as representing a key challenge in their job searching.

\section{Employment programs and Indigenous Australians}

Historically, Australian employment programs have had a 'work-first' orientation (GoodwinSmith \& Hutchinson, 2015), an approach based on the idea of moving welfare recipients into jobs as soon as possible, with minimal cost intervention, some element of compulsion and a strict focus on factors affecting employment prospects (Dean, 2003). Job Services Australia (JSA), an Australian government initiative which operated from 2009-15, was developed to provide tailored, early assistance to jobseekers (Department of Employment, 2013). As a government-funded network of organisations delivering employment services to jobseekers 
receiving income support, JSA offered personalised support according to the individual's circumstances. That is, Stream 1 funding provided support for building skills in preparation for work (e.g., resume writing, interviewing); Streams 2 and 3, for individuals with moderate disadvantage, included creating a pathway plan to improve employability; and Stream 4, for individuals with severe disadvantage, offered referrals and support to address barriers affecting employability with the overarching goal of finding and retaining work.

In 2015 government reforms saw JSA transition to a new program termed Jobactive (Department of Employment, 2016). This program is similar to the JSA in that it supports individuals currently receiving government income support. While there is a case management component, the focus is strictly work-first, with individuals required to record a specified number of job searches monthly; incentives for those who sustain employment for at least 12 months; and limited funding offered for study unless a job is guaranteed as a result. There is a jobseeker classification instrument which uses self-report and government records to identify relative difficulty in gaining and maintaining employment, and to classify individuals into streams that guide the support they receive. As with JSA Stream 4, Jobactive Stream C individuals receive support (e.g., financial counselling, parenting courses) for barriers affecting their ability to find or maintain employment.

Indigenous jobseekers could also access Community Development Employment Projects (CDEP) which used a financial incentive approach to reduce welfare dependency and the adverse effects of unemployment (Dockery \& Milsom, 2007). Although somewhat controversial (Hunter, 2009), CDEP supported people (the majority of whom were Indigenous) in remote areas by enabling organisations to redistribute unemployment benefits to provide wages to people engaged in employment related to local community development. In the early 2000s CDEP participation accounted for the majority of paid employment reported by Indigenous Australians (Hunter \& Gray, 2013). In recent years this program has undergone significant reforms to become first the Remote Jobs and Communities Program and more recently, the Community Development Programme (Department of the Prime Minister and Cabinet, 2016). The current program acts to provide personalised assistance and ensure that jobseekers are engaged in activities that benefit the community and allow them to build skills as they find work.

These programs all have a 'work-first' focus and while they acknowledge the challenge of balancing Indigenous traditions with positions in mainstream employment, they make little attempt to address factors beyond those directly relating to joblessness (Goodwin-Smith \& Hutchinson, 2015). Some Indigenous employment programs have tried to address this shortcoming, for example, the TrainingPlus program (Guenther, Castle, Raymond, \& Berschl, 2010-2011) utilised trainers as cultural brokers, supporting Indigenous participants to progress from perceiving themselves as unemployable to employable by offering counselling, assistance, practical support, training, work experience, and employment in the building, construction and renewable energies sector. While results from evaluations of previous Indigenous employment programs (including TrainingPlus) have indicated improved engagement with services and rates of employment, generally they have highlighted a need to address the broader barriers to employment that Indigenous Australians face in order to encourage sustained employment (DEEWR, 2012b; Dockery \& Milsom, 2007).

\section{The Building Family Opportunities Program}

Cognisant of these issues, the Building Family Opportunities (BFO) program took a 'life-first' approach incorporating a range of domains including health and wellbeing, community and social participation, family and household functioning, housing and living circumstances, education and/or training and employment (Moskos et al., 2014). The BFO program was an initiative of the SA Department of Premier and Cabinet and was administered by the SA Department of Further Education, Employment, Science and Technology. This was a pilot 
program delivered by non-government organisations (NGOs) in three disadvantaged local government areas in SA between 2010 and 2013. It adopted a strengths-based, holistic approach to working with individual jobseekers and their families, to address the multiple barriers they faced to participation in education and/or employment. In essence, the BFO program focused on identifying existing jobseeker and family strengths rather than deficits. An intensive case management approach was used to promote social inclusion by enabling members of long-term jobless families to participate in education, training and ultimately employment. Qualitative evidence from the program suggests that BFO participants valued the focus on both personal and vocational barriers being addressed in tandem (Walker et al., 2016). One particular focus was supporting Indigenous jobseekers, with the BFO program designed to include a minimum of $30 \%$ of families with Indigenous backgrounds in each area (Moskos et al., 2014).

The assumption of the BFO program was that participating in employment or education offers a pathway out of economic and social disadvantage, for the individual jobseeker and their family. The BFO program was voluntary; clients were not compelled to participate by the threat of any penalties (i.e., loss of benefits). Participants either self-referred or were referred by organisations such as Centrelink, SA Health (the state health department) or local service providers. Upon entry, families completed a comprehensive assessment with their assigned case manager to identify personal and family strengths, challenges and any barriers to participation and employment, understand family dynamics, and set goals.

\section{The current research}

The focus of this paper is on outcomes for Indigenous families in the BFO program. The paper addresses three research questions:

- What proportion of Indigenous BFO participants achieved education/training or employment outcomes?

- What contributed to the achievement of education/training or employment outcomes?

- What are the lessons from the BFO program for policy and service delivery to reduce Indigenous disadvantage?

\section{Method}

The study utilised both qualitative and quantitative methods with the different sources used to triangulate the data to strengthen both the credibility and applicability of the findings. Ethics approval was gained from the Flinders University Social and Behavioural Research Ethics Committee before undertaking the project.

\section{Quantitative data}

Administrative and survey data were collected by BFO case managers throughout a family's involvement. Case managers recorded socio-demographic (including Indigenous status) and health information for the family, and outcomes relating to education, training, and employment for all individual jobseekers (Moskos et al., 2014). BFO participants selfidentified as being Indigenous. This information was recorded in the data and was used to differentiate between Indigenous and non-Indigenous participants in the analysis.

To explore client complexity, a measure of complex disadvantage was constructed. Building on measures developed by the Centre for the Analysis of Social Exclusion, Stewart (2002) identified five primary domains of wellbeing (or conversely socio-economic disadvantage or exclusion): material wellbeing, social participation, education, health, and participation in productive life (including paid employment). Our measure of disadvantage addressed these 
domains and was based on administrative data and items from the survey completed by all BFO jobseekers (Isherwood, Moskos, King, Walker, \& Brown, in press).

\section{Qualitative data}

Participants were purposively selected for the qualitative interviews, that is, a list of all BFO families was obtained and stratified according to key characteristics (i.e., location, age, gender, family type and Indigenous status). All interviews with jobseekers lasted on average one hour, were digitally recorded and transcribed verbatim. Participants were compensated with a $\$ 20$ gift card for their time. Participants were asked:

- To identify any pre-existing barriers to participation in employment and/or training

- How they came to be involved in the BFO program

- Whether (and how) their involvement in the BFO program had made a difference in terms of their employment, education and training, and broader wellbeing

- Whether (and how) their involvement had impacted upon their experiences of using other social, health and employment services.

In addition, during the evaluation two focus groups were held with BFO case managers at each of the NGO sites. These focus groups explored perceptions of working on the BFO program; improvements in systems and service delivery arising from the program; models of good practice and learnings with potential for broader application; and the impact of the program upon the community within which it operated.

The qualitative data were analysed according to the 'Framework' approach (Ritchie \& Spencer, 1994). Using NVIVO the research team began familiarisation with the data through listening to recordings and reading transcripts. Following this, the team met to identify a number of a priori and emergent themes. The process of familiarisation then continued with selected transcripts. At the same time, in order to test the coding framework, two team members independently coded the transcripts against the identified themes, after which the level of agreement was assessed and the framework altered accordingly. Subsequently, emergent nodes were clarified. Coding of the whole dataset proceeded in line with the framework. During the coding process the research team made notes regarding concepts and ideas that emerged and were relevant to the mapping and interpretation phase. Patterns within the data were identified and key program elements were consequently established.

The primary objectives of the program were to: (i) increase the social and economic participation of long-term jobless families; (ii) secure sustainable employment for one or more family members; (iii) increase the participation and engagement of children and dependents (whose families were participating in the program) in education or work; and (iv) improve the responsiveness of systems and services to meet the needs of long-term jobless families in order to increase their workforce participation.

Outcomes were measured quantitatively by proportions of participants involved with education/training or employment and qualitatively by positive comments about education or employment outcomes.

\section{Results}

\section{Indigenous families in the BFO program}

Of the 347 families approved for entry into the BFO program, $32 \%$ identified as Aboriginal or Torres Strait Islander $(n=110)$. Within these families, there were 128 family members who were actively seeking work. In comparison, within the 237 non-Indigenous families, there were 265 jobseekers. Indigenous families tended to be larger and include more dependent 
children than non-Indigenous families (Table 1). The distribution of children's ages was similar for all families. Both Indigenous and non-Indigenous families included a high proportion of female jobseekers and jobseekers from single parent families.

Reflecting the objectives of the BFO program, many of the jobseekers were facing complex disadvantage, with little difference in the level of disadvantage experienced by Indigenous and non-Indigenous jobseekers. Overall, $42 \%$ of Indigenous jobseekers experienced four or more disadvantages (e.g., substance use, homelessness, disability, long-term unemployment etc.); with $45 \%$ of non-Indigenous jobseekers recording the same (Table 2 ).

\section{Education and training outcomes for families}

Through the BFO program, $40 \%$ of Indigenous and $45 \%$ of non-Indigenous participants entered education and/or training. It took Indigenous jobseekers longer to enter education and/or training (172 days on average) compared with non-Indigenous jobseekers (133 days). The majority of activities were undertaken in the VET sector $(30 \%)$ and related to Certificate I or II courses $(27 \%)$, with over a third of jobseekers studying part-time (37\%).

\section{Employment outcomes for families}

Over the program's course, $21 \%$ of Indigenous, compared to $31 \%$ of non-Indigenous, jobseekers obtained employment. Indigenous jobseekers took around the same time to obtain work (an average of 179 days) as non-Indigenous jobseekers (172 days). Overall the majority of BFO jobseekers held part-time $(64 \%)$, and casual $(65 \%)$ positions. The most common roles were labourers $(27 \%)$ or community and personal service workers $(14 \%)$.

Table 1. Profile of families participating in the BFO programa

\begin{tabular}{|c|c|c|c|c|}
\hline & \multicolumn{2}{|c|}{$\begin{array}{l}\text { Indigenous } \\
(N=110)\end{array}$} & \multicolumn{2}{|c|}{$\begin{array}{l}\text { Non-Indigenous } \\
(N=237)\end{array}$} \\
\hline & $n$ & $\%$ & $n$ & $\%$ \\
\hline Female jobseekers & 85 & 77 & 181 & 76 \\
\hline Single parent family & 80 & 73 & 175 & 74 \\
\hline \multicolumn{5}{|c|}{ No. of people within family } \\
\hline 1 & 6 & 5 & 9 & 4 \\
\hline 2 & 9 & 8 & 52 & 22 \\
\hline 3 & 25 & 23 & 62 & 26 \\
\hline 4 & 16 & 15 & 48 & 20 \\
\hline $5+$ & 54 & 49 & 66 & 28 \\
\hline \multicolumn{5}{|c|}{ No. of children within family } \\
\hline 1 & 15 & 14 & 54 & 23 \\
\hline 2 & 20 & 18 & 59 & 25 \\
\hline 3 & 26 & 24 & 51 & 22 \\
\hline 4 & 14 & 13 & 21 & 9 \\
\hline $5+$ & 20 & 18 & 22 & 9 \\
\hline Data not available & 15 & 14 & 30 & 13 \\
\hline \multicolumn{5}{|c|}{ Age of children ${ }^{\mathrm{b}}$ (years) } \\
\hline $0-4$ & 79 & 72 & 174 & 73 \\
\hline $5-15$ & 94 & 85 & 209 & 88 \\
\hline $16-24$ & 99 & 90 & 221 & 93 \\
\hline
\end{tabular}

a Due to rounding of percentages, totals may not sum to exactly 100 . 
${ }^{\mathrm{b}}$ Column percentages will not sum to 100 as families could have more than one child and therefore be assigned to more than one category.

Table 2. Number of disadvantages experienced

\begin{tabular}{lllll}
\hline & $\begin{array}{l}\text { Indigenous } \\
\text { Jobseekers } \\
(\mathbf{N = 1 2 8 )}\end{array}$ & \multicolumn{2}{l}{$\begin{array}{l}\text { Non-Indigenous } \\
\text { Jobseekers } \\
(\mathbf{N = 2 6 5 )}\end{array}$} \\
\hline & $n$ & $\%$ & $n$ & $\%$ \\
\hline 0 or $\mathbf{1}$ & 19 & 15 & 26 & 10 \\
$\mathbf{2}$ & 28 & 22 & 52 & 20 \\
$\mathbf{3}$ & 27 & 21 & 67 & 25 \\
$\mathbf{4}$ & 30 & 23 & 53 & 20 \\
$\mathbf{5 +}$ & 24 & 19 & 67 & 25 \\
\hline
\end{tabular}

\section{Qualitative data}

Thirteen jobseekers from Indigenous families participated in qualitative interviews (Table 3), and 24 case managers were involved in focus groups. Of the 13 Indigenous jobseekers interviewed, nine had engaged in education or training. These were predominantly Technical and Further Education (TAFE) Certificates II or III in areas including hospitality, child services, nursing, beauty and community services. In terms of employment, two had applied for positions, one in hospitality and one in disability support; three were volunteering at schools or local NGOs; two had been employed in short-term casual positions in aged care and one was setting up a beauty therapy business. Discussions with Indigenous jobseekers and case managers identified program elements that were key in enabling education and training or employment outcomes, as described below.

\section{Voluntary referrals}

The voluntary nature of the BFO program was unique. Families were referred through service providers including Centrelink, Indigenous services or other programs coordinated by the NGOs (for Indigenous families the latter represented the majority of referrals [37\%]). Over time there were increasing self-referrals, or families advising friends to join.

The families are happy and engaging and then referring or recommending BFO to other family members and people they know and particularly with the Aboriginal community, I think that's something to be highly recognised. (BFO staff member) 
Table 3. Profile of Indigenous families $(N=13)$ participating in qualitative interviews $^{\mathrm{a}}$

\begin{tabular}{lll}
\hline & $n$ & $\%$ \\
\hline Female & 11 & 85 \\
Male & 2 & 15 \\
Age & & \\
$\quad 18-24$ & 4 & 31 \\
$25-34$ & 2 & 15 \\
$35-44$ & 3 & 23 \\
$45-54$ & 2 & 15 \\
$\quad$ Not disclosed & 2 & 15 \\
Single parent & 9 & 69 \\
Couple family & 4 & 31 \\
\hline a Due to rounding of percentages, totals may not sum to exactly 100.
\end{tabular}

Whole families

A key strength described by participants and case managers was the BFO program's emphasis on whole families. Many of the participants had complex family arrangements; often they were single parents with multiple children, blended families, had relatives in prison, had/were temporary houseguests, or estranged relatives. Despite this complexity, valuing families, and looking out for others, consistently emerged as themes that were important to the jobseekers and supported by the BFO program. With a holistic approach case managers were able to offer support to not just individuals but all members of the family where appropriate. For example, helping to motivate other family members to undertake training courses, or liaising with schools.

\section{Strengths-based, life-first approach}

The strengths-based, life-first approach considered a range of factors affecting an individual's opportunity to engage in education/training or employment. The case managers worked to support Indigenous families by finding out what was important to them, their skills, and what was achievable. The BFO program offered a flexible, client-centred program that provided resources to address individual needs. This approach contributed to positive outcomes relating to housing, emotional and financial wellbeing, social participation, education/training, and employment.

What we do with the programs, the services, we deal with their agenda, not our agenda... the relationship with [some other employment-related agencies] is that there is this specific employment agenda and people are complying with that and it's all in that zone. Whereas we reversed the framework as saying what do you want to do? How does that fit with your range and needs? What do you need to clear first before you can achieve this? And what can we do to help you do that? (BFO staff member)

A number of jobseekers discussed the way case managers provided support when needed, and at the jobseeker's pace.

I can't focus on doing that [setting up business] for myself until I fix all these other things because they are all the other things that are stopping me ... So they had to 
be my main goals in order to get myself at the level of thinking that okay, this is what I want to do now (Female, 24yo, single)

\section{Types of support}

From the perspective of case managers the provision of socio-emotional support was crucial before more practical support could be given. This often involved case managers helping jobseekers to recognise progress and build resilience, as well as providing counselling or support in times of crisis. Socio-emotional support assisted jobseekers to improve their confidence, motivation, and self-belief. Underpinning this support was the building of trust, with the case manager representing someone the family could consistently depend on; for some clients, their case manager was the first person in their life to be 'on their team'.

One factor that contributed to building trust was the outreach approach whereby case managers visited families in locations where the families were comfortable. The format of interactions were tailored to the individual, sometimes involving text messaging or phone calls, at other times face-to-face meetings at the NGO office or the family's home depending on access and transport. Families were relieved that they could talk to their case managers whenever they required, sometimes multiple times a day when in crisis. This contributed to a sense of social inclusion, particularly as many jobseekers had been discouraged by their previous unsatisfactory interactions with the sector.

Case managers not only informed families about the services that might be of benefit to them but liaised with organisations and advocated for families. Participants described how their case managers supported them in their interactions with lawyers, health professionals, schools, housing providers and employers. Indigenous families also looked favourably on the intensive and culturally appropriate nature of the support. Where possible Indigenous workers were paired with Indigenous families and case managers were culturally responsive. For example, in negotiating with a housing organisation concerned about an Indigenous family living in 'overcrowded' conditions, the case manager explained how culturally it was preferable to have everybody under the one roof.

[Case manager] came up and she stood with me and stood her ground too as if she was like my Aunty instead of my worker (Female, 25yo, single)

From the interviews and focus groups it became apparent that practical assistance to reduce barriers to education/employment was integral to the BFO program's success. Participants described receiving financial support such as help with paying bills, teaching budgeting skills, or receiving referrals for financial counselling, and the provision of food vouchers or Christmas hampers; assistance with finding housing and relocating; and support with attaining resources such as library cards, driver's licences, uniforms, or reading glasses. When it came to education and employment specifically, case managers described how they were involved with attaining funding for courses, job/course searches, and sourcing childcare.

\section{Discussion}

There are significant inequities between Indigenous and non-Indigenous Australians, and education/training and employment are two key areas in which these inequalities are most stark. The BFO program was introduced in SA to counteract these trends. In focusing on the impact and outcomes from the BFO program for Indigenous jobseekers in particular, this paper sought to inform future initiatives to 'close the gap'. Findings indicated that as a holistic, life-first, case management program the BFO was able to assist Indigenous and non-Indigenous jobseekers in achieving their education and employment goals. 
Direct comparisons between employment programs are difficult due to variation in approaches (e.g., funding per jobseeker, caseload size, outcome measures), nevertheless BFO outcomes appear favourable when placed in the context of previous programs. At the end of 2012, $21 \%$ of Indigenous BFO jobseekers gained employment, compared to $15 \%$ of JSA Stream 4 jobseekers (a group comparable to BFO participants) (DEEWR, 2012a; Guenther et al., 2010-2011). The BFO program supported significantly more Indigenous clients to attain education and/or training positions than other programs. Only $15 \%$ of Indigenous individuals supported by JSA achieved education or training outcomes (DEEWR, 2012a) compared to $40 \%$ of Indigenous BFO participants. It is interesting to note that the BFO program outcomes for Indigenous Australians were also comparable with those for non-Indigenous jobseekers. This is not typically the case for other programs.

There are some unique aspects that may have attributed to the outcomes achieved in the BFO program for Indigenous participants. There was a focus on identifying and building upon strengths within disadvantaged families to help them on the path to employment, rather than taking a work-first approach in which typically participants' preferences are not taken into account (Walker et al., 2016). While the jobs attained by participants were predominantly on a part-time basis, in most cases this was in line with the jobseekers' goals, and with previous program outcomes e.g., CDEP (Hunter \& Gray, 2013). This must be acknowledged; it has been suggested that Indigenous culture does not put as much value on participation in paid employment as in non-Indigenous traditions (Penman, 2008) thus one of the BFO program's strengths is in the ability to design goals centred on the preferences and priorities of the jobseekers involved. It must also be noted that these outcomes were achieved in an unfavourable employment climate given the decline of the manufacturing and mining sectors in SA. Improving the outcomes further would likely require attention to some of the structural barriers to Indigenous employment, especially the importance of addressing the institutional racism that is prevalent in Australia (Paradies, 2007) and which has been shown empirically to be experienced by Aboriginal and Torres Strait Islander people in Adelaide specifically (Gallaher et al., 2009).

There is limited literature available about intensive case management as it applies to Indigenous Australians, but the current results suggest that this approach was key. While Guenther et al. (2010-2011) described the value of using case management in TrainingPlus where trainers provided this support to address work-related issues, the 'life-first' BFO case management approach offered advocacy and assistance across a wider range of social determinants. The BFO program allowed a mix of crisis management, socio-emotional support and careers counselling, giving case managers the ability to tackle all the social issues influencing the jobseekers and their often complex family challenges.

The frequent contact and multifaceted support provided by case managers offered significant motivation and encouragement for jobseekers, which in turn enabled social and economic participation (Isherwood et al., in press). The advocacy and relational components of the program were valuable in building social capital with associated benefits for attaining outcomes (Halchuk, 2006). Outreach was particularly important for Indigenous families, a population for whom there are many institutional barriers to accessing services, including previous history with government agencies (Hayman, White, \& Spurling, 2009; Weightman, 2013). The BFO program allowed for maintenance of traditional cultures within interactions with mainstream services by engaging participants as active decision makers, defining and striving to attain their own goals. In line with previous research, trusting and non-judgemental relationships in which case managers took into account family and cultural preferences were invaluable (Hunter \& Jordan, 2010; Matthews \& Burton, 2013).

While previous examples of holistic, strengths-based, family-centred approaches have illustrated success with families at risk of homelessness (MacKenzie, Desmond, \& Steen, 
2007), there has been little application of such a model in addressing long-term joblessness. As opposed to the traditional focus on deficits, the BFO program considered the jobseekers' capacity for education, training and employment. This embodies a self-determination approach which has been praised as a successful mechanism for encouraging Indigenous engagement in employment (Dockery \& Milson, 2007). The holistic approach also acknowledged the extensive social networks common among Indigenous communities who often live in multiple family households (Hetzel et al., 2004); as case managers worked with whole family units, they were able to address issues beyond the individual level.

\section{Limitations and future research}

As with any program there were challenges, with issues about engagement emerging from both the focus groups and interviews. The BFO model allowed jobseekers to be involved with the program for 18 months, providing case managers the time to build and re-build relationships, however, some jobseekers took considerable time to engage, or disengagement occurred at various points. This was typically related to client complexity or negative previous experiences with service providers (e.g., distrust, fatigue, pressure to comply), both of which were particular issues for Indigenous families, perhaps not surprising given the broader historical context of colonialism and racism in Australia. Additional challenges related to the difficulty the NGOs faced in recruiting Indigenous case managers. Two of the sites were able to employ Indigenous workers and all staff underwent cultural awareness training. However, introducing incentives to attract and retain Indigenous workers in the program may have aided in boosting families' engagement.

There are limits to what one program can do to address intergenerational disadvantage, especially when working on a case-by-case basis with individual families (Moskos et al., 2014) however, future research into initiatives that may close the gap in education/training and employment could build on the lessons from the BFO program. Such research could consider cost-benefit analysis as while intensive case management may be perceived as valuable by recipients, it is a resource-intensive approach. There would also be benefit in conducting a study that allowed for control group comparisons, or analyses that accounted for the potential influence of additional services being received by families and their level of disadvantage. It is also necessary that future studies control for the time lag between the end of training and the commencement of employment, and consider issues of retention; as beginning and staying in a job are separate activities. Additionally, it must be acknowledged that the jobs gained were mainly casual, low skill and part-time positions. Future studies could follow up satisfaction with such positions over the long-term and also seek to investigate the factors affecting recruitment and maintenance for different types of positions.

\section{Implications}

Service providers may look to incorporate some of the core elements of the BFO program in their supports to families with complex, intergenerational disadvantage, particularly Indigenous families. Intensive case management, with frequent contact and outreach, enabled the building of trust and respected relationships. Supportive organisations may also need to consider integrating advocacy into their practices, especially when working with Indigenous families. This reinforces the importance of, where possible, recruiting staff with an understanding of, and respect for, Indigenous culture, and providing cultural awareness training for those who are not familiar with these traditions (Matthews \& Burton, 2013). Embracing social inclusion principles that emphasise the important of giving families a voice and an active role in driving the processes offers an empowering, self-determined approach to reducing intergenerational disadvantage.

The BFO program's positive outcomes suggest there is value in a life-first approach. Future strategies may look to embrace more holistic, flexible and strengths-based principles that 
centre on building resilience and progressing families on the pathway to employment, rather than relying on top-down mandates around meeting mutual obligations. The BFO program's approach was distinct, offering a contrast to other services which tend to work in 'silos' (Osborne et al., 2013) and only address employment in a narrow sense. Developing policies that support integration across health and social care providers, and focus not only on employment but on other social inclusion objectives will help to encourage Indigenous families to engage with services and achieve training and employment outcomes. Halchuk (2006) described how a 'one size fits all' policy solution would be unable to adequately achieve desired outcomes given the heterogeneity in antecedents and employment outcomes among Indigenous Australians noting that instead, an empowering approach that is driven by the family's needs, is likely to have more success. Policies need to be culturally responsive, and acknowledge the values and priorities of Indigenous Australians. Future initiatives would benefit from the development of infrastructure and provision of resources (e.g., time, staffing, funding) that support outreach, advocacy and intensive case management in addressing some of the challenges currently faced by the Closing the Gap strategy. 


\section{References}

Anderson, I., Baum, F. \& Bentley, M. (eds). (2007). Beyond Bandaids: Exploring the Underlying Social Determinants of Aboriginal Health, Papers from the Social Determinants of Aboriginal Health Workshop, 2004. Darwin: Cooperative Research Centre for Aboriginal Health.

Australian Bureau of Statistics (ABS). (2009). National Aboriginal and Torres Strait Islander Social Survey, 2008. Cat. No. 4714.0. Canberra: ABS.

ABS. (2011). Australian Social Trends March 2011: Education and Indigenous Wellbeing. Cat. No. 4102.0. Canberra: ABS.

ABS. (2012). Labour Force Characteristics of Aboriginal and Torres Strait Islander Australians, Estimates from the Labour Force Survey, 2011. Cat. No. 6287.0. Canberra: ABS.

ABS. (2014). Australian Aboriginal and Torres Strait Islander Health Survey: Updated Results, 2012-13. Cat. No. 4727.0.55.006. Canberra: ABS.

ABS. (2015). Labour Force. Cat. No. 6202.0. Canberra: ABS.

ABS. (2016). National Aboriginal and Torres Strait Islander Social Survey, Australia 2014-15. Cat. No. 4714.0. Canberra: ABS.

Australian Government. (2016). Closing the Gap: Prime Minister's Report 2016. Canberra: Australian Government.

Biddle, N. \& Cameron, T. (2012). The benefits of Indigenous education: Data findings and data gaps. In B. Hunter \& N. Biddle (eds.), Survey Analysis for Indigenous Policy in Australia. Canberra: Australian National University E Press and the Centre for Aboriginal Economic Policy Research.

Carson, B., Dunbar, T., Chenhall, R. D. \& Bailie, R. (eds). (2007). Social Determinants of Indigenous Health. New South Wales: Allen \& Unwin.

Commission on Social Determinants of Health. (2007). Social Determinants and Indigenous Health: The International Experience and its Policy Implications. Report on Specially Prepared Documents, Presentations and Discussion at the International Symposium on the Social Determinants of Indigenous Health Adelaide. Paper presented at the International Symposium on the Social Determinants of Indigenous Health, Adelaide.

Council of Australian Governments. (n.d.). Closing the Gap in Indigenous Disadvantage. $\begin{array}{llll}\text { Accessed } & 21 & \text { October, } & 2014\end{array}$ https://www.coag.gov.au/closing_the_gap_in_indigenous_disadvantage

Dean, H. (2003). Re-conceptualising welfare-to-work for people with multiple problems and needs. Journal of Social Policy, 32, 441-459.

Department of Education, Employment, and Workplace Relations (DEEWR). (2012a). Labour Market Assistance Outcomes December 2012. Canberra: DEEWR.

DEEWR. (2012b). Servicing Indigenous Job Seekers in Job Services Australia. Canberra: DEEWR.

Department of Employment. (2013). Job Services Australia (JSA). Canberra: Department of Employment.

Department of Employment. (2016). jobactive. Canberra: Department of Employment.

Department of the Prime Minister and Cabinet. (2016). The Community Development Programme (CDP). Canberra: Department of Prime Minister and Cabinet.

Dockery, A. M. \& Milsom, N. (2007). A Review of Indigenous Employment Programs. Adelaide: National Centre for Vocational Education Research.

Gallaher, G., Ziersch, A., Baum, F., Bentley, M., Palmer, C., Edmondson, W. \& Winslow, L. (2009). In Our Own Backyard: Urban Health Inequities and Aboriginal Experiences of Neighbourhood Life, Social Capital and Racism. Adelaide: Flinders University.

Goodwin-Smith, I. \& Hutchinson, C. L. (2015). Beyond supply and demand: Addressing the complexities of workforce exclusion in Australia. Journal of Social Inclusion, 6, 163-185.

Gray, M., Hunter, B. \& Biddle, N. (2014). The Economic and Social Benefits of Increasing Indigenous Employment. Canberra: Centre for Aboriginal Economic Policy Research. 
Gray, M., Hunter, B. \& Lohoar, S. (2012) Increasing Indigenous Employment Rates. Canberra: Closing the Gap Clearinghouse.

Guenther, J., Castle, K., Raymond, N. \& Berschl, K. (2010-2011). Training for employment outcomes in Indigenous contexts: Straddling the space between cultures. Vocal, 8, 86-94.

Halchuk, P. (2006). Measuring employment outcomes for Indigenous Australians. Australian Journal of Labour Economics, 9, 201-215.

Hayman, N. E., White, N. E. \& Spurling, G. K. (2009). Improving Indigenous patients' access to mainstream health services: The Inala experience. Medical Journal of Australia, 190, 604-606.

Hetzel, D., Page, A., Glover, J. \& Tennant, S. (2004). Inequality in South Australia (Key Determinants of Wellbeing Vol. 1: The Evidence). Adelaide: Department of Health.

Hunter, B. (2009). A half-hearted defence of the CDEP scheme. Family Matters, 81, 43-54.

Hunter, B. \& Gray, M. (2013). Continuity and change in the Community Development Employment Projects Scheme (CDEP). Australian Journal of Social Issues, 48, 35-56.

Hunter, B. \& Jordan, K. (2010). Explaining social exclusion: Towards social inclusion for Indigenous Australians. Australian Journal of Social Issues, 45, 243-265.

Isherwood, L., Moskos, M., King, D., Walker, R. \& Brown, L. (in press). Multiple disadvantage, service delivery and client outcomes in a strengths-based employment program. Australian Bulletin of Labour.

Kendall, J. (2001). Circles of disadvantage: Aboriginal poverty and underdevelopment in Canada. American Review of Canadian Studies, 31(1-2), 43.

Lowry, D. \& Moskos, M. (2007). Labour force participation as a determinant of Indigenous health. In I. Anderson, F. Baum \& M. Bentley (eds.), Beyond Bandaids: Exploring the Underlying Social Determinants of Aboriginal Health. Papers from the Social Determinants of Aboriginal Health Workshop. Darwin: Cooperative Research Centre for Aboriginal Health.

MacKenzie, D., Desmond, K. \& Steen, A. (2007). Household Organisational Management Expenses (HOME) Advice Program: Evaluation report 2007. Canberra: Department of Families, Community Services and Indigenous Affairs.

Matthews, G. \& Burton, J. (2013). Promising practice in intensive family support for Aboriginal and Torres Strait Islander families. Developing Practice: The Child, Youth and Family Work Journal, 34, 56-66.

Moskos, M., Isherwood, L., Walker, R., Brown, L., Sun, L. \& Fitzpatrick, D. (2014). Building Family Opportunities Program Evaluation: Summary Report. Adelaide: Department for Communities and Social Inclusion.

Osborne. K., Baum, F. \& Brown, L. (2013). What works? A Review of Actions Addressing the Social and Economic Determinants of Indigenous Health. Issues Paper No. 07, Produced for the Closing the Gap Clearinghouse. Canberra: Australian Institute of Health and Welfare \& Melbourne: Australian Institute of Family Studies.

Paradies, Y. (2007). Racism. In B. Carson, T. Dunbar, R. Chenhall \& R. Bailie (eds.), Social Determinants of Indigenous Health. Crows Nest: Allen and Unwin.

Paradies, Y. \& Cunningham, J. (2009) Experiences of racism among urban Indigenous Australians: Findings from the DRUID study. Ethnic and Racial Studies, 32, 548-573.

Penman, R. (2008). Indigenous housing, family life and parental employment: A review of the literature. In Australian Government Department of Families, Housing, Community Services and Indigenous Affairs, Australian Social Policy No. 7. Canberra: Commonwealth of Australia.

Ritchie, J. \& Spencer, L. (1994). Qualitative data analysis for applied policy research. In A. Bryman \& R. Burgess (eds.), Analyzing Qualitative Data. London: Sage.

Stewart, K. J. (2002). Measuring well-being and exclusion in Europe's regions. Centre for Analysis of Social Exclusion, CASE paper 53. London: London School of Economics.

Walker, R., Brown, L., Moskos, M., Isherwood, L., Osborne, K., Patel, K. \& King, D. (2016). 'They really get you motivated': Experiences of a life-first employment program from the perspective of long-term unemployed individuals. Journal of Social Policy, 45, 507-526. 
Walter, M. \& Mooney, G. (2007). Employment and welfare. In B. Carson, T. Dunbar, R. Chenhall \& R. Bailie (eds.), Social Determinants of Indigenous Health. Crows Nest: Allen and Unwin.

Weightman, M. (2013). The role of Aboriginal Community Controlled Health Services in Indigenous health. Australian Medical Student Journal, 4, 49-52. 


\section{Biographical Notes}

Dr Lynsey Brown is a Research Fellow in the School of Medicine at Flinders University. With a background in health psychology and public health, Lynsey has worked on a range of quantitative and qualitative research projects within the South Australian Community Health Research Unit, Southgate Institute and Primary Health Care Research and Information Service (PHCRIS). Lynsey is also involved in teaching undergraduate allied health and postgraduate medicine subjects which focus on biopsychosocial approaches to health and illness. At PHCRIS Lynsey is involved in knowledge exchange and the synthesis and review of evidence on topical policy-relevant issues in primary health care.

Dr Katy Osborne is a social scientist with a background in psychology and public health. She has also worked on research projects in the areas of politics and public policy. Between 2011 and 2013 she worked as a Research Fellow in the South Australian Community Health Research Unit. Her research interests lay in the areas of gender and women's health, neighbourhood and place as social determinants of health, and how participation in different life domains such as paid work, community volunteering, unpaid domestic work and leisure influence health in different ways.

Dr Ruth Walker is a social gerontologist with a background in Public Health and Psychology. She is currently Senior Lecturer in Disability and Community Inclusion at Flinders University. Her research focuses on life transitions associated with ageing as well as the experiences of ageing parent caregivers. She is particularly interested in conducting qualitative research which gives voice to somewhat marginalised or vulnerable older people and which helps to shape practice and policy.

Dr Megan Moskos is a Research Fellow at NILS, where her work is in applied sociology and social policy. Her research interests centre on unemployment, social inclusion and low skilled work. Megan has led research on unemployment, workforce participation and social inclusion for government and non-for profit organisations including the Department of Social Services, Department of Health, Department of Veteran Affairs, South Australian Social Inclusion Unit, Mental IIIness Federation of Australia, Cooperative Research Centre for Aboriginal Health and South Australian Department of Further Education, Employment, Science and Technology. She has expertise in qualitative and quantitative methodologies and integrating the two.

Dr Linda Isherwood joined the National Institute of Labour Studies as the Karmel Foundation Research Fellow in October 2012. Her research interests centre on the aged care, disability and primary health care sectors, with a particular focus on workforce issues and program evaluation. Linda is a Fellow of the Australian Association of Gerontology. She is a mental health social worker who has worked extensively in community and hospital settings in Australia and the United Kingdom.

Katherine Patel is a public health researcher at Flinders University, with interests in the social determinants of health, gender and health, community health and digital inclusion. She is experienced in program evaluation, training and mentoring across government, community health and the non-government sectors. She has a background in SA Health's HIV and hepatitis C Unit, and the Port Pirie Lead Program. Kate and her husband established Parklands Dental in 2011, where she is the practice manager. 
Professor Fran Baum is a Matthew Flinders Distinguished Professor of Public Health and Director of the Southgate Institute of Health, Society and Equity at Flinders University. She was named in the Queen's Birthday 2016 Honours List as an Officer of the Order of Australia (AO) for "distinguished service to higher education as an academic and public health researcher, as an advocate for improved access to community health care, and to professional organisations". Professor Baum is a Fellow of the Academy of the Social Sciences in Australia, and one of Australia's leading researchers on the social and economic determinants of health.

Associate Professor Debra King is a sociologist in the School of Social and Policy Studies at Flinders University and was previously a Principal Researcher at the National Institute of Labour Studies (2007-2013). While at NILS she led several projects including the Building Family Opportunities Project (until 2013) and the aged care workforce census and survey. Her research interests include workforce participation, the care workforce and the emotional characteristics of work.

\section{Acknowledgements/Conflict of interest}

This research is based on work undertaken as part of an evaluation of the Building Family Opportunities program, a Department of Premier and Cabinet initiative administered by the Department of Further Education, Employment, Science and Technology (DFEEST), in South Australia. All listed authors were active members of the team responsible for undertaking the evaluation. The authors thank Lulu Sun and Darcy Fitzpatrick (NILS) for their assistance with the quantitative analyses. 